\title{
昡pubvet
}

https://doi.org/10.31533/pubvet.v14n11a685.1-7

\section{Heme Acquisition by trypanosomatids: Evaluation of the heme- dependent behavior and its biochemical implications}

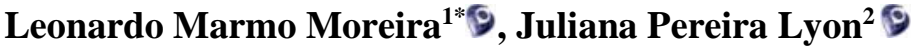 \\ ${ }^{1}$ Departamento de Zootecnia (DEZOO), Universidade Federal de São João del-Rei (UFSJ), São João del-Rei, Minas Gerais, Brazil. \\ ${ }^{2}$ Departamento de Ciências Naturais (DCNAT), Universidade Federal de São João del-Rei (UFSJ), São João del-Rei, Minas Gerais, Brazil. \\ *Author for correspondence, E-mail: leonardomarmo@gmail.com
}

\begin{abstract}
The inability of some species to produce porphyrin-like compounds induces these species to search for blood to fulfill their heme requirement. The biological cycle of very relevant parasites, such as Leishmania sp. and Trypanossoma sp., is directly related to the search for heme. The understanding of this process in a chemical and biochemical approach is a pre-requisite to obtaining advancements regarding hemoprotein structureactivity relationships as well as molecular aspects of various pathological/physiological mechanisms associated with parasitary and/or blood diseases, between others. The present work presents an overview of the chemical/biochemical properties of porphyrin, heme, heme proteins, and parasitary diseases caused by Trypanossomatidae. We believe that this kind of discussion can contribute significantly to improve the understanding of the structure-function relation of these complex diseases.
\end{abstract}

Keywords: Trypanossomatidae, hemoprotein, porphyrin-like compounds, parasitary diseases, heme synthesis failure

\section{Aquisição de heme por tripanossomatídeos: Avaliação do comportamento heme-dependente e suas implicações bioquímicas}

Resumo. A incapacidade de algumas espécies de produzir compostos semelhantes à porfirina induz essas espécies a procurar sangue para atender aos requisitos de heme. $\mathrm{O}$ ciclo biológico de parasitas muito relevantes como Leishmania sp. e Trypanossoma sp., está diretamente relacionado à busca pelo heme. A compreensão desse processo em uma abordagem química e bioquímica é um pré-requisito para se obter avanços na relação estrutura-atividade das hemoproteínas, bem como nos aspectos moleculares dos diversos mecanismos patológicos/fisiológicos associados a doenças parasitárias e/ou hematológicas, entre outras. $\mathrm{O}$ presente trabalho abrange uma visão geral sobre as propriedades químicas/bioquímicas da porfirina, heme, hemoproteínas e doenças parasitárias causadas por Trypanossomatidae. Acreditamos que esse tipo de discussão pode contribuir significativamente para melhorar o entendimento da relação estrutura-função dessas doenças complexas.

Palavras chave: Trypanossomatidae; hemoproteína; compostos tipo porfirina; doenças parasitárias; falha na síntese do heme

\section{Introduction}

Hemoflagellate parasite, such as Trypanossoma and Leishmania, can infect human beings, domestics, and sylvatic animals, being associated with some of the more severe parasitary diseases. Both genera belong to the protozoan family known as Trypanossomatidae, class of Kinetoplastidae. 
Mammals are a reservoir for Leishmania sp. being that infected dogs consist of a well recognized public health problem. Thousands of dogs use to be culled every year in Brazil when the parasite is detected (Dantas-Torres et al., 2019b). However, better alternatives have arose, like vaccines, insect repellents, and drug treatment (Dantas-Torres et al., 2019a).

American trypanosomiasis can affect the dog, being the disease characterized by heart conditions (Arce-Fonseca et al., 2017). Besides, dogs have been implicated as an important domestic reservoir for T. cruzi. Estrada-Franco et al. (2006) established a correlation between seropositivity in humans and dogs in Mexico. Elmayan et al. (2019) observed that this parasite is widespread in shelter dogs from Louisiana, USA. Similarly, Arce-Fonseca et al. (2017) found a serologic prevalence of T. cruzi of $4.44 \%$ of domestic dogs from Sonora, Mexico.

Leishmaniasis is a neglected disease found in tropical and subtropical areas. The clinical manifestations involve cutaneous leishmaniasis and visceral leishmaniasis. According to the CDC (Center for disease control, 2020), the disease affects from 700.000 to 1.200 million people per year and, in the case of the visceral leishmaniasis, there are 400.00 or more new cases per year. Leishmania is transmitted to mammals through the inoculation of the protozoan promastigotes by the sand fly vector. The promastigotes are phagocyted by macrophages and turn into amastigotes, which multiply and infect any cell of mammal organism. If a sandfly bites an infected mammal, it becomes infected, the amastigote turns into promastigotes and this cycle goes on. In this context, it is important to notice that the most dangerous form of Leishmania is visceral leishmaniasis; left untreated, it is fatal in more than $95 \%$ of cases (Singh et al., 2018). For most Leishmania species, the iron acquisition, which involved a very complex mechanism (receptors, ferric reductases, and a divalent cation transporter), has been poorly described (Zaidi et al., 2017).

Trypanosoma cruzi is the etiological agent of Chagas disease, also known as American trypanosomiasis. The disease is mainly transmitted by the feces of a triatomine insect that harbor $T$. cruzi (trypomastigotes) in its digestive tract. The parasite reaches the host by the wound that is caused by the bite of the insect and penetrates cells at this site. Inside the cells, trypomastigotes turn into amastigotes and multiply. Amastigotes turn into trypomastigotes, burst the cell, and infect other cells. Triatomines get infected by biting an infected mammal. Chagas disease is prevalent in Central and South America, where there are about 8 million people infected. About $30 \%$ of the infected people will develop symptoms that include severe cardiac disease, enlarged colon, and enlarged esophagus (CDC, 2020).

\section{The incomplete heme synthesis in trypanosomatids and the requirement of hemes from mammals}

Most trypanosomatids lack a complete heme biosynthetic pathway and must acquire heme from external sources (Sengupta et al., 1999). Leishmania spp., for instance, are heme auxotrophs, containing only the last three steps of heme synthesis and must rely on host heme or heme precursors (LaranjeiraSilva et al., 2020). Indeed, aerobic organisms are generally able to synthesize heme through a conserved metabolic pathway composed of eight (8) steps (Orrego et al., 2019).

In the animal host, heme is present as hemopexin and, mainly, hemoglobins. This potential source may be available when erythrocytes are lysed by hemolysins or the natural degradation of hemoglobin in macrophages or by hitherto unknown mechanisms. It is important to note that hemoglobin-binding proteins have been identified in some pathogens, suggesting that selective recognition of hemoglobin occurred at the cell surface (Sengupta et al., 1999).

Although the parasites need heme to develop its biological functions, the free-heme can also be harmful. Indeed, the triatomine, which is the vector of $T$. cruzi in Chagas disease, ingest blood from a mammal and, subsequently, this blood becomes source of free-heme in the insect's gut. The presence of this compound propagates Reactive Oxygen Species (ROS), which affects the biologic differentiation of $T$. cruzi. An oxidant environment must stimulate epimastigote proliferation and an antioxidant environment promotes metacyclogenesis (Nogueira et al., 2015). Ferreira et al. (2018) suggested that heme undergoes a crystallization process in the gut of the insect that is both a protective process to $T$. cruzi and the triatomine.

Receptor systems have been identified on trypanosomatids parasites, which mediate uptake of lowdensity lipoprotein and transferring presumably for efficient supply of nutrients required for rapid 
growth, such as cholesterol and metallic ions, which usually occur as tightly bound complexes with carrier proteins (Sengupta et al., 1999). However, it is not well understood how these parasites obtain heme as well as the mechanism associated with the heme, which makes that this cofactor is distributed inside the cell of this trypanosomatid (Tripodi et al., 2011). In any case, they contain hemoproteins, such as cytochromes, that are involved in fundamental metabolic pathways, which probably is associated with all biochemical and physiological mechanisms (Tripodi et al., 2011).

In this context, it is interesting to notice that some insect-infecting trypanosomatids can survive in culture without heme, while others cannot (Alves et al., 2011). It has been observed that the promastigote forms of Leishmania major grow up in the absence of any heme source (Orrego et al., 2019). In agreement with Alves and co-workers, this ability is related to the presence of a beta proteobacteria endosymbiont in the flagellate cytoplasm, despite the respective mechanism is not still well understood (Alves et al., 2011).

Bloodstream trypomastigotes are ingested by the vector and transform into replicative epimastigotes in the lumen of the gut, which is rich in hemoglobin and heme (Lara et al., 2007). In nature, T. cruzi must acquire extracellular heme from their hosts as a nutritional cofactor and incorporate it into various essential hemoproteins (Lara et al., 2007).

There are other species of Trypanosoma that have received the attention of several researchers due to their intrinsic importance as well as to evaluate similar and distinct physiological, biochemical, and behavior properties in comparison with Trypanosoma cruzi. Trypanosoma rangeli, for example, is a hemoflagelate parasite that infects domestics and sylvatic animals as well as human beings. In a similar way to other trypanosomatids, $T$. rangeli depends on the heme in culture for its growth and differentiation. The study of this parasite is very interesting, being used to evaluate common aspects with Trypanosoma cruzi.

\section{Survival mechanisms of Trypanossomatids}

Interesting studies focused on Leishmania donovani have elucidated aspects of the survival mechanisms of this parasite. Cytochrome P450s (CYP450s) are hemoproteins catalyzing diverse biochemical reactions important for the metabolism of xenobiotics and synthesis of physiologically important compounds, such as sterols. Therefore, they are functionally important for the survival of invading pathogens, such as Leishmania donovani (Verma et al., 2011). Indeed, for survival within host cells, parasites are required to eliminate host generated oxidative stress products, maintain biosynthesis of essential molecules, and resist lethal drugs.

It is important to notice that as a consequence of the high levels of haemin and related porphyrins, which present an important cytotoxic action through the generation of reactive oxygen species (ROS), such as superoxide anion $\left(\mathrm{O}_{2}{ }^{-}\right)$, hydrogen peroxide $\left(\mathrm{H}_{2} \mathrm{O}_{2}\right)$, and the highly reactive hydroxyl radical $(\mathrm{OH})$, it has been investigated the effect of haemin on the growth of T. cruzi (Ciccarelli et al., 2007). The impact of the called "photodynamic action" (generation of oxidative species through the light incidence and excitation of dyes, in this case, in the biological medium) against trypanosomatids is an interesting question to evaluate aspects related to the adaptation of this kind of parasite to the blood environment. Earlier studies have shown that both the promastigote and the amastigote forms of Leishmania donovani are sensitive to oxidative and nitrosative stress and use specialized defense systems unique to themselves to survive when exposed to such conditions (Verma et al., 2011).

In this context, it is interesting to notice that photodynamic therapy (PDT) has been applied with methylene blue (MB) as a dye (photosensitizer) and Light Emitting Diode (LED) as a light source against Leishmania. These components constitute a very inexpensive system, which would be a very interesting pre-requisite to elaborate a therapeutic alternative, mainly against a parasite as Leishmania. In fact, this therapeutic strategy promoted a significant reduction in the size of the lesions, in the parasitic load in the draining lymph node and healed the lesions in hamsters experimentally infected with $L$. amazonensis (Peloi et al., 2011).

The mechanism of action of antimonial drugs remained unclear for more than 60 years of its effective use against all forms of leishmaniasis. Earlier reports indicate that antimonials, probably, act by inhibiting glycolysis and fatty acid $\beta$-oxidation or by a process of apoptosis involving DNA 
fragmentation and externalization of phosphatidylserine. Subsequently, trivalent antimony ( $\mathrm{Sb}(\mathrm{III})$ ) was shown to inhibit both trypanothione reductase and glutathione synthetase (Biyani et al., 2011).

Recent studies have described various mechanisms in parasite biochemistry that are involved in antimonial sensitivity. Pentavalent form $(\mathrm{Sb}(\mathrm{V}))$ is reduced to a more toxic trivalent form ( $\mathrm{Sb}(\mathrm{III})$ ), which constitutes the active form of the drug against the parasite. Parasite thiols (trypanothione, glutathione) are considered to have a critical role in the process of detoxification of heavy metals in trypanosomatids. These thiol levels have been related to the amplification of the enzymes involved in the synthesis of glutathione (glutamylcysteine synthetase, GSH1) and polyamines (ornithine decarboxylase), the precursor molecules of trypanothione. Another potential part of antimony detoxification is the conjugation of metal with a thiol, a process mediated by glutathione-S-transferase (GST) (Biyani et al., 2011). In this context, the biological behavior of dependence of heme in culture, regarding its growth and differentiation, is a very interesting aspect of the physiological properties of several species of Trypanossoma, with respect to a great number of interdisciplinary and multidisciplinary areas, such as parasitology, biochemistry, bioinorganic chemistry, cellular biology, and others.

\section{Iron Storage and heme synthesis}

The heme synthesis in trypanossoma cruzi was evaluated as a function of the medium conditions. Salzman and co-workers identified a great influence of the medium conditions upon the action of enzymes, which was affected by the substrates employed in this study (Salzman et al., 1986).

Considering the human being as host, it is important to comment upon the mechanisms and factors that affect the iron homeostasis in the mammalian hosts, especially human beings (Manta et al., 2012). The great majority of iron ions (ferric and ferrous ions) is the mammalian biological medium, which is a substrate to the synthesis of hemoproteins, such as hemoglobin and myoglobin; and iron-sulfur (Fe-S) proteins. The two processes of protein synthesis take place frequently in the mitochondria, which represents the principal intracellular compartment for iron ions (mainly, $\mathrm{Fe}(\mathrm{II})$ and $\mathrm{Fe}$ (III) ions) use (Manta et al., 2012; Levi \& Rovida, 2009). Iron ions, such as ferric and ferrous ions, are stored through binding with ferritin heteropolymers, in which can be encountered up to 4500 ferric ions $\left(\mathrm{Fe}^{3+}\right)$ (Andrews, 2010; Manta et al., 2012).

\section{Understanding the Physico-chemical properties of Heme}

It is important to register that the porphyrins and their several types of metallic complexes have been investigated for many years because of the richness of the properties of these compounds and the interest of porphyrins and metalloporphyrins to a wide range of scientific disciplines, from medicine to materials science. Metalloporphyrins in living systems play many functions essential for life, and the elucidation of both the geometric and electronic structures of these compounds is of extreme relevance to a detailed understanding of their roles in biological systems. Moreover, the possibility of mimicking the complex chemistry exhibited by metalloporphyrins in living organisms with synthetic models propitiates the possibility of exploiting then in a wide range of different applications, from medical diagnostics and treatments to catalysts and sensors (Andrews, 2010).

The heme groups (iron porphyrins) sites are involved in a range of biological functions, including electron transfer (e.g., cytochromes $a, b, c$, and $f$ ), in which the heme cycle between low-spin Fe(II) and low-spin $\mathrm{Fe}$ (III) small-molecule binding and transport, catalysis, and $\mathrm{O}_{2}$ activation (e.g. peroxidases and cytochromes P450), where high-valent iron centers are involved in hydrogen atom abstraction, hydroxylation, and epoxide formation. Heme sites are significantly different from non-heme iron sites, in which the porphyrin ligand allows for the delocalization of the iron d-electrons into the porphyrin $\pi$ system. This fact changes the nature of the iron regarding the flexibility of the central coordination site, the energetics of reactivity, and, consequently, its biological function (Hocking et al., 2007).

The structure-activity relationship of iron-porphyrins in association with the structure-function one of globins is still a great challenge to several researchers. In fact, this extraordinary hemoprotein system is widely distributed in nature, presenting slight differences between the several types of heme proteins. In spite of the similar Physico-chemical properties, the a priori apparently small significant differences 
are responsible for a diversity of characteristics that becomes quite distinct the biochemical behavior of these proteins.

The nitrophorins constitutes an example of this complex reality since these proteins are a group of NO-carrying hemoproteins encountered in the saliva of, at least, two species of blood-sucking insects, Rhodnius prolixus and Cimex lectularius, which present very interesting and elaborated Physicochemical properties deeply associated to its complex biochemical role (Berry \& Walker, 2008; Knipp et al., 2007). These hemoproteins sequester nitric oxide (NO), which is produced by an enzyme called nitric oxide synthase (NOS), that is present in the cells of the salivary glands (similar to vertebrate constitutive NOS). NO is kept stable for long periods by ligation as the sixth ligand of the ferriheme center. Upon injection into the tissues of the victim, NO dissociates, diffuses through the tissues to the nearby capillaries to cause vasodilatation, and, thereby, allows more blood to be transported to the respective site of the wound. At the same time, histamine, whose role is to cause swelling, itching, and initiating the immune response, is released by mast cells and platelets of the victim. In the case of the Rhodnius proteins, this histamine binds to the heme iron sites of the nitrophorins, hence preventing the victim detection of the insect for a period, which allows it to obtain a sufficient blood meal (Berry \& Walker, 2008; Knipp et al., 2007).

The great and crescent number of studies that employ porphyrin-like compounds in different chemical contexts denotes the extraordinary interdisciplinary and multidisciplinary characters of these macrocyclic compounds. The applications of porphyrin-like compounds, metallated or not, in PDT (Moreira et al., 2008), catalysis, electrochemical studies, biomimetic studies, and others are a definitive fingerprint of the great biochemical and Physico-chemical relevance of this area.

Primitive vertebrates and invertebrates have various types of hemoglobin that appear in forms from monomer to oligomer or polymer and present remarkably different quaternary structures and several properties of oxygen affinities. Indeed, a number of crystal structures of invertebrate monomeric, oligomeric, and polymeric hemoglobins are available, and all these hemoglobins demonstrate quite a different assemblage from mammalian hemoglobins (Numoto et al., 2008). It is also important to notice that the heme groups are extremely determinant of the life of several species due to the vital roles of myoglobins, cytochromes, and other hemoproteins.

\section{Final considerations}

The heme synthesis consists of a complex sequence of chemical reactions. This process with various chemical steps is of fundamental relevance to the life of mammalians, not being completely developed in Trypanossoma, which is related to the biological cycle of this relevant parasite. We believe that the understanding of some Physico-chemical aspects of heme synthesis as well as the Trypanossoma biological cycle constitutes a pre-requisite to optimize strategies to control the respective parasitary diseases.

\section{References}

Alves, J. M. P., Voegtly, L., Matveyev, A. V., Lara, A. M., Silva, F. M., Serrano, M. G., Buck, G. A., Teixeira, M. M. G., \& Camargo, E. P. (2011). Identification and Phylogenetic Analysis of Heme Synthesis Genes in Trypanosomatids and Their Bacterial Endosymbionts. PLoS ONE, 6(8), e23518. https://doi.org/10.1371/journal.pone.0023518

Andrews, S. C. (2010). The Ferritin-like superfamily: Evolution of the biological iron storeman from a rubrerythrin-like ancestor. Biochimica et Biophysica Acta (BBA) - General Subjects, 1800(8), 691705. https://doi.org/10.1016/j.bbagen.2010.05.010

Arce-Fonseca, M., Carrillo-Sánchez, S. C., Molina-Barrios, R. M., Martínez-Cruz, M., Cedillo-Cobián, J. R., Henao-Díaz, Y. A., \& Rodríguez-Morales, O. (2017). Seropositivity for Trypanosoma cruzi in domestic dogs from Sonora, Mexico. Infectious Diseases of Poverty, 6(1), 120. https://doi.org/10.1186/s40249$\underline{017-0333-\mathrm{Z}}$

Berry, E. A., \& Walker, F. A. (2008). Bis-histidine-coordinated hemes in four-helix bundles: how the geometry of the bundle controls the axial imidazole plane orientations in transmembrane cytochromes of mitochondrial Complexes II and III and related proteins. JBIC Journal of Biological 
Inorganic Chemistry, 13(4), 481-498. https://doi.org/10.1007/s00775-008-0372-9

Biyani, N., Singh, A. K., Mandal, S., Chawla, B., \& Madhubala, R. (2011). Differential expression of proteins in antimony-susceptible and -resistant isolates of Leishmania donovani. Molecular and Biochemical Parasitology, 179(2), 91-99. https://doi.org/10.1016/j.molbiopara.2011.06.004

Centers for Disease Control and Prevention (CDC). https://www.cdc.gov/parasites/chagas/ Access in Apr 2020.

Ciccarelli, A., Araujo, L., Batlle, A., \& Lombardo, E. (2007). Effect of haemin on growth, protein content and the antioxidant defence system in Trypanosoma cruzi. Parasitology, 134(7), 959-965. https://doi.org/10.1017/S0031182007002399

Dantas-Torres, F., Miró, G., Baneth, G., Bourdeau, P., Breitschwerdt, E., Capelli, G., Cardoso, L., Day, M. J., Dobler, G., Ferrer, L., Irwin, P., Jongejan, F., Kempf, V. A. J., Kohn, B., Lappin, M., Little, S., Madder, M., Maggi, R., Maia, C., ... Otranto, D. (2019a). Canine Leishmaniasis Control in the Context of One Health. Emerging Infectious Diseases, 25(12), 1-4. https://doi.org/10.3201/eid2512.190164

Dantas-Torres, F., Miró, G., Bowman, D. D., Gradoni, L., \& Otranto, D. (2019b). Culling Dogs for Zoonotic Visceral Leishmaniasis Control: The Wind of Change. Trends in Parasitology, 35(2), 97 101. https://doi.org/10.1016/j.pt.2018.11.005

Elmayan, A., Tu, W., Duhon, B., Marx, P., Wolfson, W., Balsamo, G., Herrera, C., \& Dumonteil, E. (2019). High prevalence of Trypanosoma cruzi infection in shelter dogs from southern Louisiana, USA. Parasites \& Vectors, 12(1), 322. https://doi.org/10.1186/s13071-019-3572-y

Estrada-Franco, J. G., Bhatia, V., Diaz-Albiter, H., Ochoa-Garcia, L., Barbabosa, A., VazquezChagoyan, J. C., Martinez-Perez, M. A., Guzman-Bracho, C., \& Garg, N. (2006). Human Trypanosoma cruzi Infection and Seropositivity in Dogs, Mexico. Emerging Infectious Diseases, 12(4), 624-630. https://doi.org/10.3201/eid1204.050450

Ferreira, C. M., Stiebler, R., Saraiva, F. M., Lechuga, G. C., Walter-Nuno, A. B., Bourguignon, S. C., Gonzalez, M. S., Azambuja, P., Gandara, A. C. P., Menna-Barreto, R. F. S., Paiva-Silva, G. O., Paes, M. C., \& Oliveira, M. F. (2018). Heme crystallization in a Chagas disease vector acts as a redoxprotective mechanism to allow insect reproduction and parasite infection. PLOS Neglected Tropical Diseases, 12(7), e0006661. https://doi.org/10.1371/journal.pntd.0006661

Hocking, R. K., Wasinger, E. C., Yan, Y.-L., DeGroot, F. M. F., Walker, F. A., Hodgson, K. O., Hedman, B., \& Solomon, E. I. (2007). Fe L-Edge X-ray Absorption Spectroscopy of Low-Spin Heme Relative to Non-heme Fe Complexes: Delocalization of Fe d-Electrons into the Porphyrin Ligand. Journal of the American Chemical Society, 129(1), 113-125. https://doi.org/10.1021/ja065627h

Knipp, M., Yang, F., Berry, R. E., Zhang, H., Shokhirev, M. N., \& Walker, F. A. (2007). Spectroscopic and Functional Characterization of Nitrophorin 7 from the Blood-Feeding Insect Rhodnius prolixus Reveals an Important Role of Its Isoform-Specific N-Terminus for Proper Protein Function. Biochemistry, 46(46), 13254-13268. https://doi.org/10.1021/bi7014986

Lara, F. A., Sant'Anna, C., Lemos, D., Laranja, G. A. T., Coelho, M. G. P., Reis Salles, I., Michel, A., Oliveira, P. L., Cunha-e-Silva, N., Salmon, D., \& Paes, M. C. (2007). Heme requirement and intracellular trafficking in Trypanosoma cruzi epimastigotes. Biochemical and Biophysical Research Communications, 355(1), 16-22. https://doi.org/10.1016/j.bbrc.2006.12.238

Laranjeira-Silva, M. F., Hamza, I., \& Pérez-Victoria, J. M. (2020). Iron and Heme Metabolism at the Leishmania-Host Interface. Trends in Parasitology, 36(3), 279-289. https://doi.org/10.1016/j.pt.2019.12.010

Levi, S., \& Rovida E. (2009). The role of iron in mitochondrial function. Biochimica et Biophysica Acta (BBA) - General Subjects, 1790(8), 629-636. https://doi.org/10.1016/j.bbagen.2008.09.008.

Manta, B., Fleitas, L., \& Comini, M. (2012). Iron metabolism in pathogenic trypanosomes. In Iron Metabolism. In Tech Press.

Moreira, L. M., Santos, F. V., Lyon, J. P., Maftoum-Costa, M., Pacheco-Soares, C., \& Silva, N. S. (2008). Photodynamic Therapy: Porphyrins and Phthalocyanines as Photosensitizers. Australian Journal of Chemistry, 61(10), 741. https://doi.org/10.1071/CH08145

Nogueira, N. P., Saraiva, F. M. S., Sultano, P. E., Cunha, P. R. B. B., Laranja, G. A. T., Justo, G. A., Sabino, K. C. C., Coelho, M. G. P., Rossini, A., Atella, G. C., \& Paes, M. C. (2015). Proliferation 
and Differentiation of Trypanosoma cruzi inside Its Vector Have a New Trigger: Redox Status. PLOS ONE, 10(2), e0116712. https://doi.org/10.1371/journal.pone.0116712

Numoto, N., Nakagawa, T., Kita, A., Sasayama, Y., Fukumori, Y., \& Miki, K. (2008). Structural Basis for the Heterotropic and Homotropic Interactions of Invertebrate Giant Hemoglobin. Biochemistry, 47(43), 11231-11238. https://doi.org/10.1021/bi8012609

Orrego, L. M., Cabello-Donayre, M., Vargas, P., Martínez-García, M., Sánchez, C., Pineda-Molina, E., Jiménez, M., Molina, R., \& Pérez-Victoria, J. M. (2019). Heme synthesis through the life cycle of the heme auxotrophic parasite Leishmania major. The FASEB Journal, 33(12), 13367-13385. https://doi.org/10.1096/fj.201901274RR

Peloi, L. S., Biondo, C. E. G., Kimura, E., Politi, M. J., Lonardoni, M. V. C., Aristides, S. M. A., Dorea, R. C. C., Hioka, N., \& Silveira, T. G. V. (2011). Photodynamic therapy for American cutaneous leishmaniasis: The efficacy of methylene blue in hamsters experimentally infected with Leishmania (Leishmania) amazonensis. Experimental Parasitology, 128(4), 353-356. https://doi.org/10.1016/j.exppara.2011.04.009

Salzman, T. A., Batlle, A. M. D. C., \& Souza, W. (1986). Heme synthesis in Trypanosoma cruzi: Influence of the strain and culture medium. Comparative Biochemistry and Physiology Part B: Comparative Biochemistry, 83(1), 57-61. https://doi.org/10.1016/0305-0491(86)90331-7

Sengupta, S., Tripathi, J., Tandon, R., Raje, M., Roy, R. P., Basu, S. K., \& Mukhopadhyay, A. (1999). Hemoglobin Endocytosis in Leishmania Is Mediated through a 46-kDa Protein Located in the Flagellar Pocket. Journal of Biological Chemistry, 274(5), 2758-2765. https://doi.org/10.1074/jbc.274.5.2758

Singh, N., Ahmad, Z., Baid, N., \& Kumar, A. (2018). Host heme oxygenase-1: Friend or foe in tackling pathogens? IUBMB Life, 70(9), 869-880. https://doi.org/10.1002/iub.1868

Tripodi, K. E. J., Bravo, S. M. M., \& Cricco, J. A. (2011). Role of Heme and Heme-Proteins in Trypanosomatid Essential Metabolic Pathways. Enzyme Research, 2011, 1-12. https://doi.org/10.4061/2011/873230

Verma, S., Mehta, A., \& Shaha, C. (2011). CYP5122A1, a Novel Cytochrome P450 Is Essential for Survival of Leishmania donovani. PLoS ONE, 6(9), e25273. https://doi.org/10.1371/journal.pone.0025273

Zaidi, A., Singh, K. P., \& Ali, V. (2017). Leishmania and its quest for iron: An update and overview. Molecular and Biochemical Parasitology, 211, 15-25. https://doi.org/10.1016/j.molbiopara.2016.12.004

Article History:

Received 27, May 2020

Accepted 24 June 2020

Available online 23 October 2020
License information: This is an open-access article distributed under the terms of the Creative Commons Attribution License 4.0, which permits unrestricted use, distribution, and reproduction in any medium, provided the original work is properly cited. 